\title{
ACTIIUNEA ERBICIDULUI TRIFLURALIN ASUPRA MICROMICETELOR
}

\author{
Moldovan $C$. \\ Institutul de Microbiologie şi Biotehnologie \\ Tina--92@mail.ru
}

\begin{abstract}
NCNM were tested and cultivated on Czapek medium with $20 \%$ glucose in the presence of trifluralin in concentrations of: $50 ; 100$ and $200 \mathrm{mg} / 1$. It was found that all strains growth on all tested media regardless of the concentration of trifluralin supplemented in the agar medium. In order to better highlight the action of trifluralin on micromycetes in subsequent research, glucose was excluded from the Czapek medium and the dose of trifluralin was increased from $200 \mathrm{mg} / 1$ to 300 and $500 \mathrm{mg} / 1$, so it was shown that out of 12 strains studied 6 no growth on glucose-free Czapek medium, and supplementation of this medium with trifluralin helps to stimulate their growth.
\end{abstract}

Keywords: Micromycetes, trifluralin, screening, stimulator, glucose, carbon source.

\section{Introducere}

Agricultura modernă cunoaşte o dezvoltare productivă, în special, datorită unor măsuri eficiente de protecţie a culturilor agricole de boli, dăunători şi buruieni. Aplicarea la timp a pesticidelor asigură sporirea producţiei agricole cu circa $20 \%$.Pesticidele au devenit un factor ecologic antropic de acţiune permanentă. Prezenţa microorganismelor în sol poate influenţa distribuţia, mobilitatea şi concentraţia acestor substanţe având la bază un proces numit biodegradare. Pesticidele, odată ajunse în sol, pe lângă acţiunea lor asupra bolilor, dăunătorilor, buruienilor, îşi extind acţiunea şi asupra microorganismelor. [6, 2]

Nevoia de a studia interacțiunea pesticidelor cu microflora din sol se datorează celui mai important rol al microorganismelor în crearea fertilităţii solului și în detoxifierea solului. Principala încărcare a pesticidelor din sol este preluată de microorganisme, care, datorită diversității speciilor şi aparatelor enzimatice, sunt capabile să utilizeze parțial sau complet produse chimice pentru protecția plantelor. După cum știți, pesticidele reduc activitatea microbiologică a solului, crescând astfel efectul toxic, în urma căruia actioneaza asupra microorganismele solului în timpul descompunerii substanțelor chimice Numeroase studii au arătat că pesticidele în diferite concentrații pot inhiba creșterea anumitor grupuri de microorganisme sau pot stimula dezvoltarea acestora. În această privință, una dintre sarcinile urgente ale biotehnologiei moderne este crearea de produse biologice bazate pe tulpini distrugătoare obținute din microfloră pentru a rezolva un complex de probleme asociate cu reabilitarea solurilor contaminate.[4,5]

Trifluralin este un erbicid utilizată în mod obişnuit, este una dintre cele mai utilizate erbicide. Acesta controlaeaza buruienile care germineaza. Trifluralin este utilizat in sol preplantă selectiv pentru controlul de lunga durata a unor soiuri de graminee anuale şi germinare buruieni foioase în culturile agricole şi horticole. Printre comportamentele mai neobişnuite ale trifluralinului este inactivare în soluri umede.[1,3]

Scopul cercetărilor a constat în studierea acţiunii trifluralinului asupra micromicetelor.

\section{Materiale şi metode}

Ca obiect de studiu au servit 50 tulpini de micromicete din CNMN a Institutului de Microbiologie şi Biotehnologie al AŞM. Cultivarea tulpinilor de micromicete, pe medii agarizate, s-a efectuat în termostat la temperatura de $28^{\circ} \mathrm{C}$, timp de 14 zile. Pentru determinarea purităţii culturile au fost examinate vizual după caracterele morfo-culturale, cît şi la microscop. 
Tulpinile de micromicete din CNMN au fost cultivate pe mediul agarizat Czapek cu 20ml/1 glucoza in prezeănța trifluralinei in concentrație de $50(\mathrm{mg} / \mathrm{l}) ; 100(\mathrm{mg} / \mathrm{l}) ; 200(\mathrm{mg} / \mathrm{l})$, cît și pe acelasi mediu Czapek fara glucoza cu concentratia trifluralinei de 300 si $500 \mathrm{mg} / \mathrm{l}$ pe medii agarizate,. Cultivarea tulpinilor de micromicete s-a efectuat în termostat la temperatura de $28^{\circ} \mathrm{C}$, timp de 14 zile. Cultivarea în medii lichide (submersp) s-a efectuat pe agitator timp de 7 zile cu $160 \mathrm{r} /$ minut, la temperatura de $28-30^{\circ} \mathrm{C}$. Creșterea și dezvoltarea micromicetelor în prezența trifluralinei pe medii solide a fost examinată visual.

\section{Rezultate şi discuţii}

Pentru determinarea acţiunii erbicidului trifluralin asupra microorganismelor au fost testate 50 de tulpini de micromicete din CNMN care au fost cultivate pe mediul Czapek cu $20 \%$ glucoză în prezenţa trifloralinului în concentraţii de: 50; 100 si $200 \mathrm{mg} / \mathrm{l}$. Rezultatele obţinute sun prezentate în Figura1.

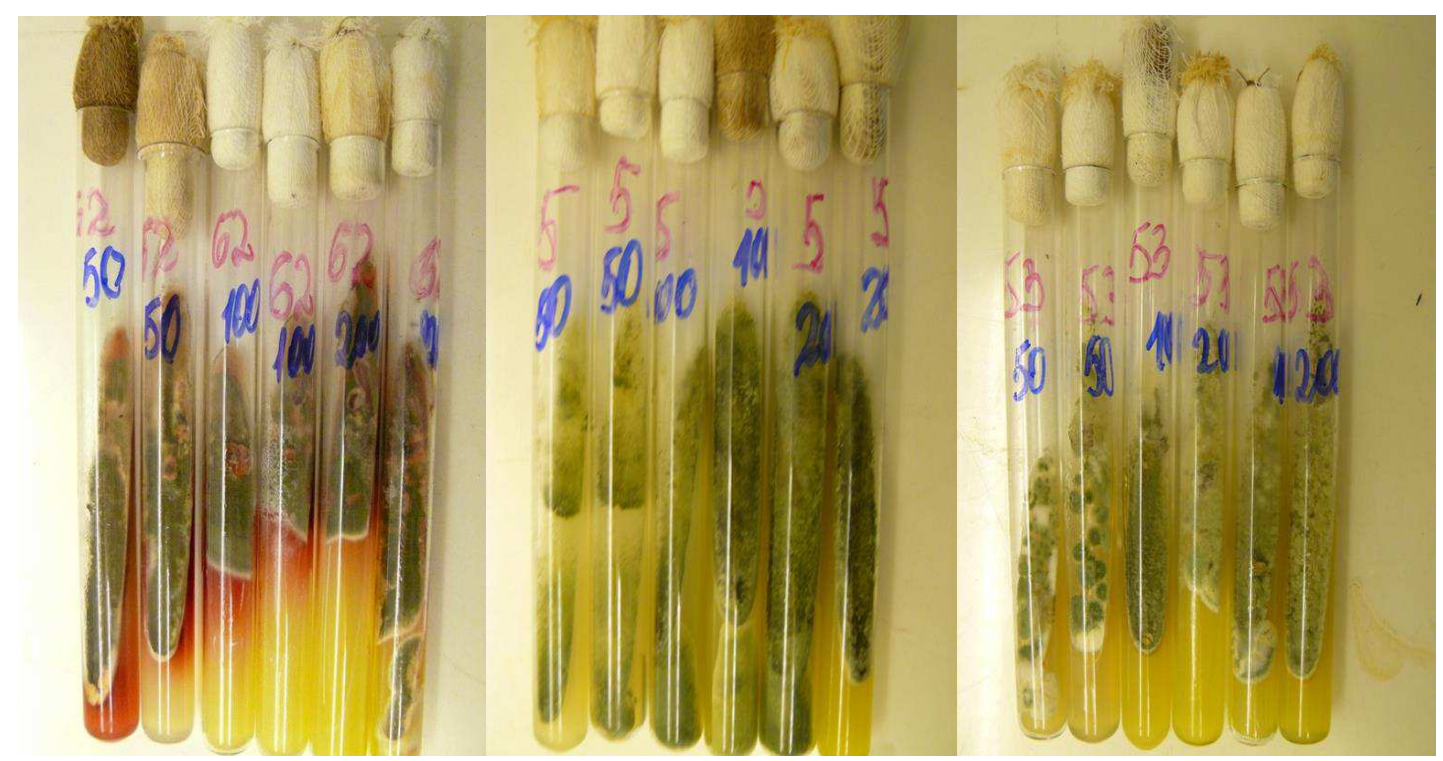

Figura 1 :Cresterea tulpinlor P.sp5; Psp 62; P.sp 53 şi P.sp. 91. pe mediul Czapek cu 20\% glucoza suplimentat cu diferite concentratii de trifloralina.

Sa constata, ca toate tulpnile testate cresc și se dezvoltă pe toate mediile testate indiferent de concentraţia trifloralinului suplimentat în mediul agarizat, dar nivelul de creştere şi dezvoltare al micromicetelor este diferit. (Figura 1). Trifluralinul în cazul dat a acționat nu ca inhibitor al cresterii micromicetelor, dar asupra unor culturi mai mult ca un stimulator, sau poate ca o sursa suplimentară de carbon, stimulînd astfel creşterea şi dezvoltarea lor.

Rezultatele prezentate în Figura 2 demonstrează, că odată cu majorarea concentraţiei de trifluralin în mediul nutritiv de la $50 \mathrm{mg} / \mathrm{l}$ la $200 \mathrm{mg} / \mathrm{l}$, procentul tulpinilor ce cresc bine se măreşte respectiv de la $34 \%$ pînă la $40 \%$. Pe mediul cu concentrația minimă de trifluralin (50mg/l) 34\% din numărul tulpinilor luate în studiu cresc bine, $36 \%$ au o creştere medie şi $30 \%$ de tulpini cresc slab. La concentraţia maximă de trifluralin, în mediul de cultivare, procentul tulpinilor ce cresc slab a rămas acelaşi ca şi la concentraţia mimiă de $50 \mathrm{mg} / 1$ - 30\%. Pentru a observa mai bine acţiunea trifluralinului asupra creşterii şi dezvoltării micromicetelor în cercetările ulterioare a fost exclusă glucoza din mediul Czapek si marită doza de trifluralin de la $200 \mathrm{mg} / \mathrm{l}$ pina la 300 si $500 \mathrm{mg} / \mathrm{l}$. 


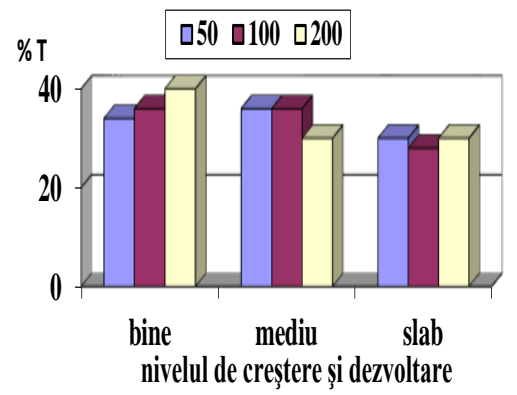

Figura 2. Screnengul micromicetelor capabile de crestere si dezvoltare in prezenta trifluralinei

Rezultatele prezentate în Tabelul 1 demonstrează, că din 12 tulpini luate în studiu 6 nu cresc pe mediul Czapek fără glucoză, iar suplimentarea acestui mediu cu trifluralin contribuie la stimularea creşterii acestora. Astfel, pe mediile cu trifluralin indiferent de concentraţia testată s-a observat o creştere lentă a tuturor tulpinilor de micromicete. Pe mediul Czapek fără glucoză suplimentat cu trifluralin în concentraţie de $200 \mathrm{mg} / 1 \mathrm{sau} 300 \mathrm{mg} / 1 \mathrm{~s}-\mathrm{a}$ constatat creşterea şi dezvoltarea lentă a tuturor tulpinilor luate în studiu. Mărind doza de trifluralin la $500 \mathrm{mg} / \mathrm{l}$ observăm unele schimbări. Tulpinile ce cresc pe mediul Czapek fără glucoză acţionează diferit la prezenţa dozelor mari de trifluralin suplimentate în mediul de cultivare. Astfel, la 4 tulpini: Sp.5, Sp.15, Sp.62 şi Sp 65, în prezenţa trifluralinului, în concentraţie de $500 \mathrm{mg} / \mathrm{l}, \mathrm{s}$-a înregistrat o creștere mai intensă, iar la 4 nu s-a înregistrat nici o modificare a creşterii.

Tabelul 1. Creşterea tulpinilor de micromicete pe mediu agarizat Czapek fără glucoză suplimentat cu diferite concentraţii de trifluralin.

\begin{tabular}{|c|c|c|c|c|c|}
\hline N/o & Tulpina & \multirow{2}{*}{$\begin{array}{c}\text { Mediu fără } \\
\text { glucoză }\end{array}$} & \multicolumn{3}{|c|}{ Concentraţia trifloralinei mg/l } \\
\cline { 4 - 5 } & & + & 200 & 300 & 500 \\
\hline 1 & Sp.5 & - & + & + & ++ \\
\hline 2 & Sp. 11 & - & + & + & + \\
\hline 3 & Sp.14 & + & + & + & + \\
\hline 4 & Sp.15 & - & + & + & ++ \\
\hline 5 & Sp.19 & + & + & + & + \\
\hline 6 & Sp.23 & - & + & + & + \\
\hline 7 & Sp.28 & + & + & + & + \\
\hline 8 & Sp.40 & - & + & + & + \\
\hline 9 & Sp.44 & + & + & + & ++ \\
\hline 10 & Sp.62 & + & + & + & ++ \\
\hline 11 & Sp.65 & - & + & + & + \\
\hline 12 & Sp.91 & & & \\
\hline
\end{tabular}

Rezultatele obţinute demonstrează, că tulpinile de micromicete sunt capabile să se adapteze foarte uşor la condiţiile mediului ambiant, şi pot utiliza în calitate de sursă de carbon diferite substanţe ce le înconjoară.

\section{Concluzii}

Conform rezultatelor obţinute putem concluziona, că acţiunea trifluralinului asupra micromicetelor este diferită. Acest erbicid poate acționa atât ca stimulator, cât și ca imhibitor 
ai creșterii. În unele cazuri trifluralinul poate srervi ca sursă suplimentară de carbon. Suplimentat în mediul Czapek agarizat este neutru, iar în unele cazuri stimulează creşterea lor.

\section{Bibligrafie}

1. Lipşa, F., Ulea, E., Chiriac, I. P., Coroi, I. G. Effect of herbicide S-metolachlor on soil microorganisms. Lucrări Științifice, Universitatea de Stiinte Agricole Și Medicină Veterinară "Ion Ionescu de la Brad" Iași, Seria Agronomie 2010, V. 53 No.2 pp.110-113.

2. Đukić, D. A. ; Sebić, A. S. ; Mandić, L., Pešaković, M. , Zelenika, M. , Đurović, V.,Bošković, I. Effect of herbicides on cellulolytic activity of soil micromycetes. : IX International Scientific Agriculture Symposium "AGROSYM 2018", Jahorina, Bosnia and Herzegovina. 2018. pp.1608-1613.

3. Аванесян ,Р.В., Пикушова ,Э.А. влияние гербицидных технологий зернотравяно-пропашном севообороте на количество почвенных микромицетов в агроценозе озимой пшеницы. Научно-техническое творчество молодежи кубанского ГАУ Краснодар, 2017, с 129-133.

4. Зайнитдинова, Л.И., Косимов ,Д.И. ,Ташпулатов Ж.Ж. ,Куканова С.И. влияние пестицидов на микробиоценозы и ферментативную активность сероземов, Химия и биология" 2019, № 11, с.65.

5. Bugă, Aurelia. Cercetări privind influența aplicării fertilizanților chimici și a pesticidelor asupra activității biologice și asupra altor proprietăți ale solurilor din câmpia Crişurilor. Rezumatul tezei de doctorat BRAŞOV, 2010, pag-5-7

6. Tolocichina,S., Cincilei.A., Sireţanu,L., Mamaliga,L.schimbările în complexul microbian al solului la aplicarea erbicidelor ştiinţa agricolă, nr. 1/2008, pag 14-17. 